\title{
Epidemiology of Breast Cancer - Current Figures and Trends
}

\section{Epidemiologie des Mammakarzinoms - aktuelle Zahlen und Trends}

Authors

Affiliations
N. Eisemann ${ }^{1}$, A. Waldmann ${ }^{2}$, A. Katalinic ${ }^{1,2}$

${ }^{1}$ Institut für Krebsepidemiologie e. V., Lübeck

${ }^{2}$ Institut für Klinische Epidemiologie, Lübeck

\author{
Key words \\ - breast cancer \\ - epidemiology \\ - prevalence \\ - incidence \\ - prognosis \\ mortality

Schlüsselwörter
- Brustkrebs
Epidemiologie
- Prävalenz
- Inzidenz
- Prognose
- Mortalität

received 19.10.2012

revised 14.11.2012

accepted 22.11.2012

Bibliography

DOI http://dx.doi.org/

10.1055/s-0032-1328075

Geburtsh Frauenheilk 2013; 73 :

130-135 @ Georg Thieme

Verlag KG Stuttgart · New York .

ISSN 0016-5751

\section{Correspondence}

Nora Eisemann

Institut für Krebsepidemiologie

Ratzeburger Allee 160 (Haus 50)

23538 Lübeck

nora.eisemann@uksh.de

\section{Abstract}

The epidemiology of breast cancer has clearly changed in the past few years. On the basis of current data from population-based cancer registries characteristic numbers for incidence, prevalence, mortality and survival after breast cancer are presented. The number of incident cases has increased to around 72000 in 2009 (+23\% since 2003). It is estimated that at present 250000 women with a prevalent breast cancer (5-year prevalence) are living in Germany. The most frequent localisation is the outer upper quadrant of the breast. Poorly differentiated or undifferentiated tumour tissue is found in every third patient. Since 2003 the age-standardised mortality has declined slightly $(-9 \%)$ whereas the relative survival has improved from 79 to $86 \%$. Changes in the epidemiology of breast cancer can most probably be attributed to the introduction of early detection programmes such as mammography screening as well as to improved treatment options. To what extent mammography screening will lead to a further reduction of mortality remains to be seen.

\section{Introduction \\ $\nabla$}

Breast cancer as the most frequent tumour disease in women is of special relevance. It is currently found that one woman in every eight will be faced with the diagnosis of breast cancer in her lifetime. While, just a few decades ago, this diagnosis was mostly associated with a fatal prognosis, nowadays most of the patients can experience a normal life expectancy. This is due mainly to advances in treatment as well as to improved early detection [1].

The changes in the fields of early detection of and treatment for breast cancer have had a decisive

\section{Zusammenfassung \\ $\nabla$}

Die Epidemiologie des Mammakarzinoms hat sich in den letzten Jahren deutlich verändert. Anhand aktueller Daten aus epidemiologischen Krebsregistern werden Kennzahlen zu Inzidenz, Prävalenz, Mortalität und Überleben nach Brustkrebs präsentiert. Die Anzahl an Neuerkrankungen ist auf rund 72000 in 2009 gestiegen (+23\% seit 2003). Es wird geschätzt, dass derzeit 250000 Frauen mit einem prävalenten Brustkrebs (5-Jahres-Prävalenz) in Deutschland leben. Die häufigste Lokalisation ist der äußere obere Quadrant der Brust. Ein schlecht differenziertes oder undifferenziertes Tumorgewebe wird bei jeder 3. Patientin gefunden. Seit 2003 ist die altersstandardisierte Mortalität leicht gesunken (-9\%), während sich das relative Überleben von 79 auf $86 \%$ verbessert hat. Veränderungen in der Epidemiologie des Mammakarzinoms dürften insbesondere auf Früherkennungsmaßnahmen wie die Einführung des Mammografie-Screenings, aber auch auf verbesserte Therapien zurückzuführen sein. Inwiefern das Mammografie-Screening zur einer weiteren Mortalitätsreduktion beitragen kann, bleibt abzuwarten.

impact on the epidemiology of breast cancer [1, 2]. Since 2005 women aged between 50 and 69 years of age are invited to participate in a mammography screening programme every second year, whereby more asymptomatic tumours are detected and treated at an early stage [3]. In the field of imaging diagnostics advances have been made that facilitate the correct and early diagnosis. Technical innovations such as digital tomosynthesis, by which tumours can be visualised three-dimensionally, have reduced the number of false-positive and false-negative findings [47]. The experience and new knowledge of the past decades have been collected in an S3 guideline 
and provide the attending physician with recommendations for evidence-based treatment options $[8,17]$. In addition, the patients are being increasingly treated in certified breast cancer centres $[19,20]$. By concentrating the therapeutic facilities in such centres more highly specialised treatment can be provided. Trends and changes in epidemiological cancer data will be discussed below

\section{Incidence and Mortality in Germany \\ $\nabla$}

In 2008 in Germany almost 72000 women suffered from an invasive breast cancer ( Table 1 ); this corresponds to a crude incidence rate of about 171.1 per 100000 women. In addition there were 6500 women with in situ tumours of the breast (crude rate 15.5/100000 women). Age-standardised, 123.8 of 100000 women were faced with the diagnosis of an invasive and 11.1 of 100000 women with that of an in situ breast cancer (European Standard Population) [2]. The patients were on average 65 years old at the time of diagnosis, whereby patients with an in situ diagnosis were on average 6 years younger ( Table 1 ). In the same year 17000 patients died of breast cancer (crude rate 41.1/ 100000 women). The age-standardised mortality rate amounted to 24.0 per 100000 (European Standard Population) [2,9].

Within Germany there are regional differences in the incidence and mortality rates of breast cancer. The incidence rate is lowest in the eastern federal states whereas in the north (SchleswigHolstein) the highest rate is seen. Mortality is also lowest in the eastern federal states, followed by slightly higher rates in the southern federal states (Bavaria, Baden-Württemberg, Hesse) and the highest mortality rates are seen in the north-western federal states [10].

- Fig. 1 shows the time trend of incidence and mortality in Germany. The incidence was relatively constant up to 2006 but thereafter it increased markedly. In 2009 it was 18\% higher than in 2003, this corresponds to an increase of 18.7 cases per 100000 women. The most important cause for the increased incidence is the introduction of mammography screening. The first screening units started to send invitations for breast cancer screening in 2005. In the following years further screening units were founded and the area coverage of the existing units improved. In 2007 about $50 \%$ of the regions and since 2008 almost all regions in Germany are supplied with screening units with area coverage of $75-100 \%$ [3]. Accordingly the large incidence jump from 114 per 100000 in 2007 to 124 per 100000 in 2008 can be attributed to the achievement of total area coverage with the thus associated increased participation in mammography screening and the detection of prevalent tumours. In the period from 1998 on breast cancer mortality has declined continuously with an average annual reduction in mortality of 1-2\%. Compared with 1998 , when the age-standardised mortality rate amounted to 28.8 deaths per 100000 women, the mortality in 2008 is about $14.6 \%$ lower, i.e., 4.2 per 100000 women less die of breast cancer. This situation is remarkable. On the one hand it points to a markedly better treatment. On the other hand it could also be due to intensified efforts in breast cancer diagnostics and early detection. Unfortunately there is no unambiguous distinction or, respectively, reliable data on the assignment of the effect to therapy and to early detection.

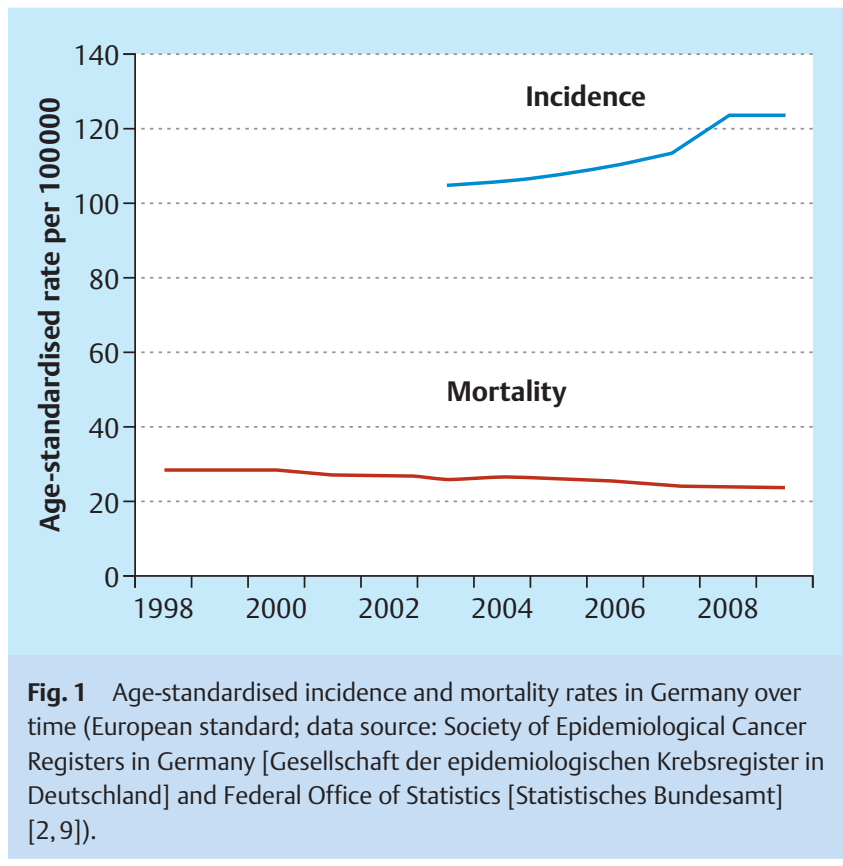

Table 1 Breast cancer epidemiology in Germany 2008/2009 (data source: Centre for Cancer Register Data [Zentrum für Krebsregisterdaten [ZFKD\}], Society of Epidemiological Cancer Registers in Germany [Gesellschaft der epidemiologischen Krebsregister in Deutschland e. V. [GEKID\}] and Federal Office of Statistics [Statistisches Bundesamt]).

\begin{tabular}{|c|c|c|}
\hline Incidence & ZFKD 2008 & GEKID 2009 \\
\hline \multicolumn{3}{|l|}{ average age at disease onset } \\
\hline - invasive & 65 & \\
\hline in situ & & $59^{*}$ \\
\hline \multicolumn{3}{|l|}{ Incidence } \\
\hline \multicolumn{3}{|l|}{ - invasive } \\
\hline number of cases & 71660 & 71874 \\
\hline crude rate, per 100000 & 171.1 & 171.6 \\
\hline ASR [E], per 100000 & 123.1 & 123.8 \\
\hline \multicolumn{3}{|l|}{ - in situ } \\
\hline number of cases & 6500 & \\
\hline crude rate, per 100000 & 15.5 & \\
\hline ASR [E], per 100000 & & $13.3^{* *}$ \\
\hline \multicolumn{3}{|l|}{ 5-year survival } \\
\hline absolute & $78 \%$ & \\
\hline relative & $86 \%$ & \\
\hline \multicolumn{3}{|l|}{ 5-year prevalence } \\
\hline number of cases & 273000 & \\
\hline crude rate, per 100000 & 685,3 & \\
\hline Mortality & Statistische & esamt 2009 \\
\hline average age at death & $71: 2$ & \\
\hline \multicolumn{3}{|l|}{ mortality } \\
\hline number of cases & 17066 & \\
\hline crude rate, per 100000 & 40,9 & \\
\hline - ASR [E], per 100000 & 23,4 & \\
\hline
\end{tabular}

ASR $[E]=$ age standardised rate according to European standard

Data source when not otherwise stated: ZFKD [1], GEKID [2],

Statistisches Bundesamt [9].

* Data source: data set of the Epidemiological Cancer Register Schleswig-Holstein (Epidemiologisches Krebsregister Schleswig-Holstein), data status as per October 2012.

** Data source: Katalinic et al. [14] 


\section{Tumour Stages}

$\nabla$

Today the majority of breast tumours is diagnosed in an early stage. Of the newly diagnosed patients about $40 \%$ were in stage T1 in 2007/2008 according to data from population-based cancer registries (excl. DCO cases). The discovered tumours had a maximum size of $2 \mathrm{~cm}$. About $30 \%$ of the patients have tumours greater than $2 \mathrm{~cm}$ but less than maximally $5 \mathrm{~cm}$ in size (stage T2). About $4 \%$ or, respectively $5 \%$ of the newly diagnosed patients are in stages T3 and T4. The stage was not known in about $13 \%$ [1]. In $9 \%$ of the cases the breast cancer was already detected in its early form as carcinoma in situ. Thus there are about 11 invasive tumours for each in situ tumour.

Even before the introduction of mammography screening there was a more favourable stage distribution among women in the age group eligible for screening in comparison to the general female population (proportion of T1 46 vs. $40 \%$ ). Since the relative distribution of tumour stages has little value for evaluation of a screening (an absolute increase in the number for favourable stages results in an apparent percent decline in unfavourable stages), in the following paragraphs the changes in absolute numbers of diseased patients according to tumour stage will be considered [11]. Between 2002 and 2007 the absolute number of breast cancer diagnoses increased markedly (without death certificate reports but including in situ cases, altogether by $15 \%$ ): for in situ tumours by $+94 \%$, for T 1 tumours by $+18 \%$, for $\mathrm{T} 2$ tumours by $+11 \%$, for T3 tumours by $+14 \%$ and for tumours of unknown stage by $+24 \%$ whereas a decrease of about $-10 \%$ was observed for T4 tumours [3].

On account of the possibility of biases, the interpretation of these data must be made with caution. Unsystematic screening had probably influenced the epidemiology of breast cancer and also tumour stage distribution even before the introduction of organised mammography screening, whereby the effect of mammography screening could appear to be markedly smaller. Furthermore, it must be considered that current data are not yet available nationwide (Baden-Württemberg and Hesse are still lacking) and that there are certainly differences in the quality of data among the existing registries. Even so, the data already encompass $79.6 \%$ of the women eligible for screening. In spite of these uncertainties, the reported decrease in the absolute number of breast cancer patients in the prognostically unfavourable T4 stage, which is responsible for the majority of deaths, can be interpreted as indication for a possible reduction in mortality. Besides the desired effect of mammography screening, a reduction in the number of deaths due to breast cancer, indications for less desirable effects are also apparent; the large increase in prognostically favourable tumours (above all the great increase in in situ carcinomas) could be an indication of an over-diagnosis and thus of over-therapy. For the situation in Germany a possible over-diagnosis through the mammography screening programme cannot yet be quantified; a very recent review assumes, on the basis of randomised controlled trials, an over-diagnosis rate of $11 \%$ or, respectively, 19\% [12].

\section{Survival}

$\nabla$

In comparison with cancer in general, breast cancer (depending on stage) has today a good prognosis. Thus, $78 \%$ of the newly affected women survive for the following five years [1]. However, this so-called absolute 5-year survival rate does not take into consideration that some of the breast cancer patients also die of other causes. The so-called relative 5-year survival, which only considers the proportion of deaths that occur in addition to the normal mortality, is markedly higher for breast cancer patients than the absolute mortality and amounts to $86 \%$. Of 100 women who would have survived for 5 years without a breast cancer, 86 women also survive this time period with or in spite of their breast cancer disease. In 2002/2003 the relative survival, however based only on data from the cancer register of the Saarland, still amounted to $79 \%[13]$.

\section{Age Groups \\ $\nabla$}

With increasing age the risk to be afflicted by breast cancer also increases ( Fig. 2). Up to the age of 30 years breast cancer is a rare disease whereas in 2008 the highest incidence rates with over 400 per 100000 were seen in the age groups 60 to 64 years and 65 to 69 years.

- Fig. 3 illustrates the time trend of incidence for those women aged 50 to 69 years who are eligible for screening as well as that for the groups of younger and older women. In 2003, 39 of 100000 women aged between 30 and 39 years and 135 of 100000 women aged between 40 and 49 years were diagnosed with breast cancer. In both groups the rate has risen slowly since then ( +15 and $+7 \%$, respectively). Prior to the start of screening activities breast cancers were detected in about 275 of 100000 women aged between 50 and 69 years. In this group that is now eligible for screening, in comparison to younger women, a pronounced increase of about $+27 \%$ can be seen. Before the start of screening activities the incidence for the oldest age groups was about 360 per 100000 women and has decreased since 2006 to about 300 per 100000 .

Also presented in Fig. 3 is the development of mortality in the 4 age groups for the same period. A decreasing trend can be observed in all groups, amounting on average to about $-2 \%$ per year. The decline in 2007 of the age-standardised mortality rate by $7 \%$ in the age group eligible for screening, which corresponds to a decrease of 4.2 deaths per 100000 women, is striking. Since deviations of this magnitude in the average mortality changes could also be of a coincidental nature, we cannot directly assume a causal relationship with a positive effect of mammography screening.

\section{Histology, Localisation and Degree of Differentiation} $\nabla$

Apart from a few exceptions, breast cancer tumours are mainly adenocarcinomas (98.8\%). The most frequent location of the cancer is the upper outer quadrant of the afflicted breast. The tumour is found in this location in every third patient (36.1\%) (data set of the epidemiological cancer register of Schleswig-Holstein, 2008; status as per October 2012). This is followed by the upper inner quadrant and the lower outer quadrant as the next most frequent sites of tumour origin (9.4 and 5.8\%, respectively). In one of 19 women (5.2\%) the tumour is found in the lower inner quadrant or almost as often (4.5\%) in the central portion of breast. The mamilla and the axillary recess are only rarely afflicted ( 0.7 and $0.3 \%$, respectively). Several overlapping sections are found in every 9 th women $(11.4 \%)$.

The grading of the tumour tissue is important for the prognosis and treatment. Well differentiated tissue is associated with a bet- 


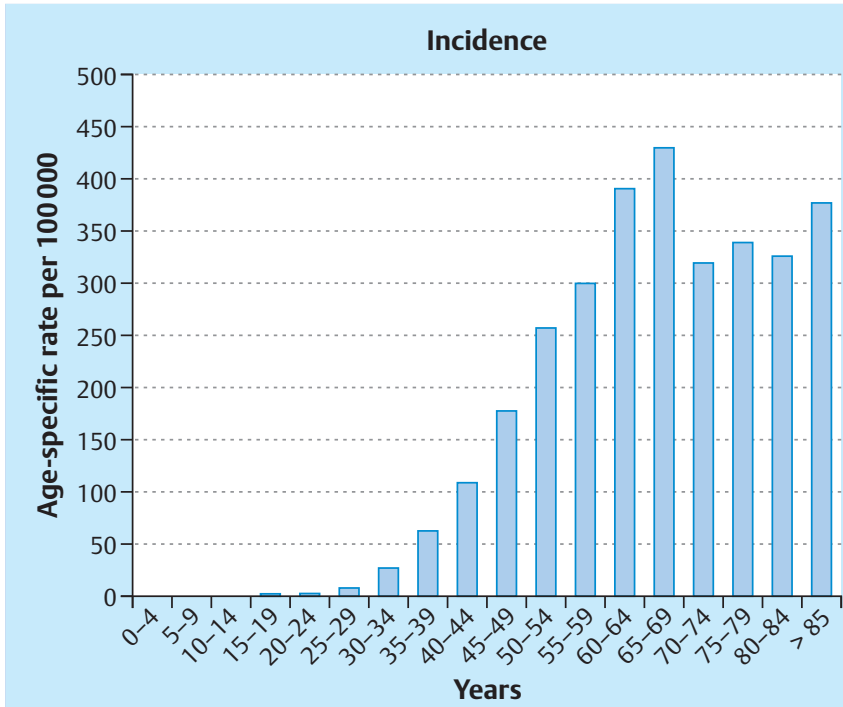

Fig. 2 Age-specific incidence and mortality per 100000 in 2008 (data source: Society of Epidemiological Cancer Registers in Germany [Gesellschaft

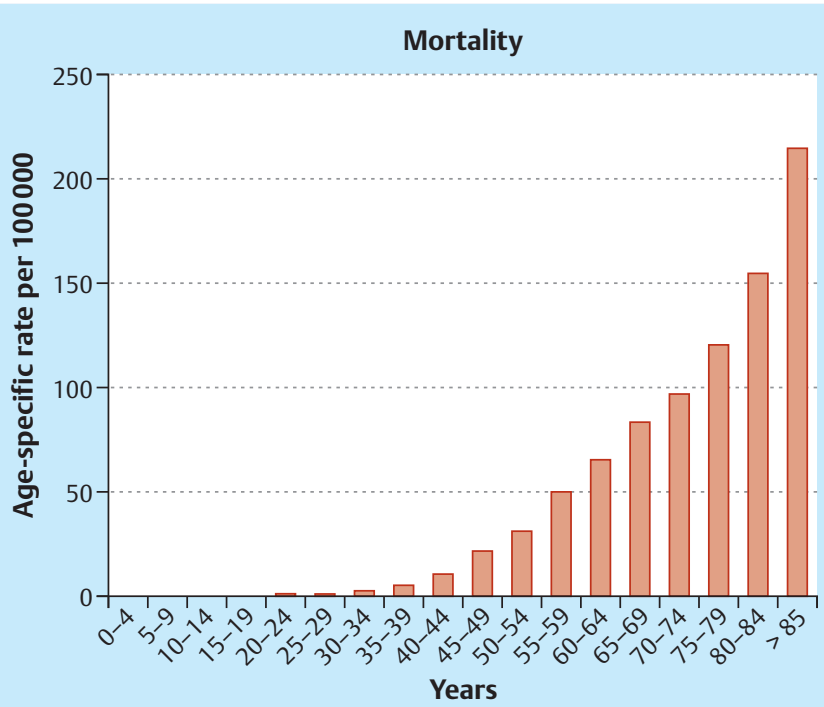

der epidemiologischen Krebsregister in Deutschland] and Federal Office of Statistics [Statistisches Bundesamt] [2,9]). ter prognosis than poorly differentiated tissue. In every 8th patient $(12.5 \%)$ diagnosed with breast cancer in 2008 in SchleswigHolstein, the biopsy revealed well differentiated tissue. In over half of the women the tumour tissue was moderately differentiated (54.3\%), and in almost every 3rd patient (30.0\%) poorly differentiated tissue was found. Undifferentiated tissue was only rarely detected $(0.3 \%)$. In $2.9 \%$ of the patients the grading could not be determined or was unknown [16].

\section{International Comparison}

Worldwide, the number of new cases of breast cancer per year is estimated to be 1.38 million, of these 450000 are in Europe [14]. Developing countries show clearly lower incidence rates than the industrialised countries ( $\bullet$ Abb. 4). The highest incidence rates are found in West Europe with 89.7 new cases per 100000 women (world standard), the lowest rates occur in Africa with about 20 cases per 100000 women. Even so breast cancer is at the top of the list of frequency of cancer diseases in all countries. The regional differences in breast cancer mortality are much smaller (between 6 and 19 deaths per 100000) than the differences in incidence because patients in countries with a very high incidence often have a very good prognosis. Not only in most of the developing countries but also in the industrialised nations breast cancer is still the most frequent cause of death due to cancer among women [14].

The 5-year prevalence in Europe is between about 250 and 850 per 100000 women [15]. The highest rates are found in central Europe and Scandinavia ( $\mathbf{F i g . 5}$ ). High incidence rates and a

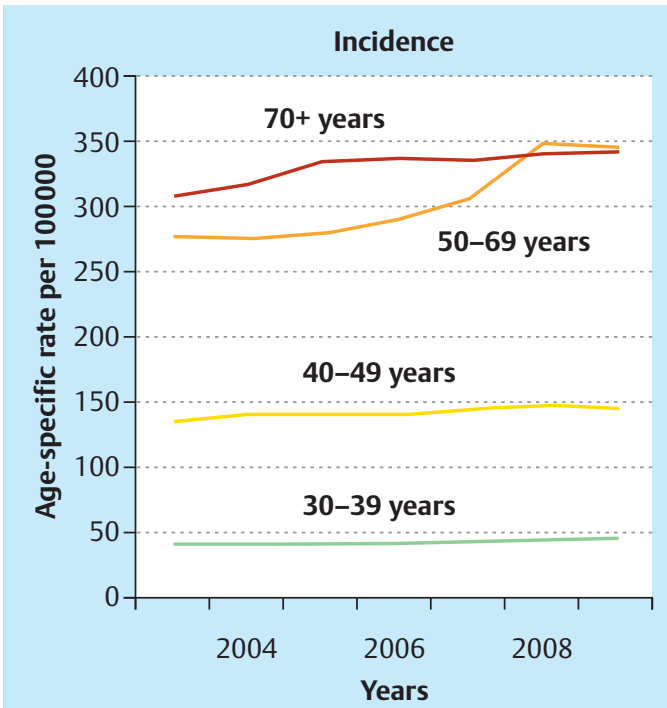

Fig. 3 Crude incidence and mortality rates in Germany according to age group over time (data source: Society of Epidemiological Cancer Registers in

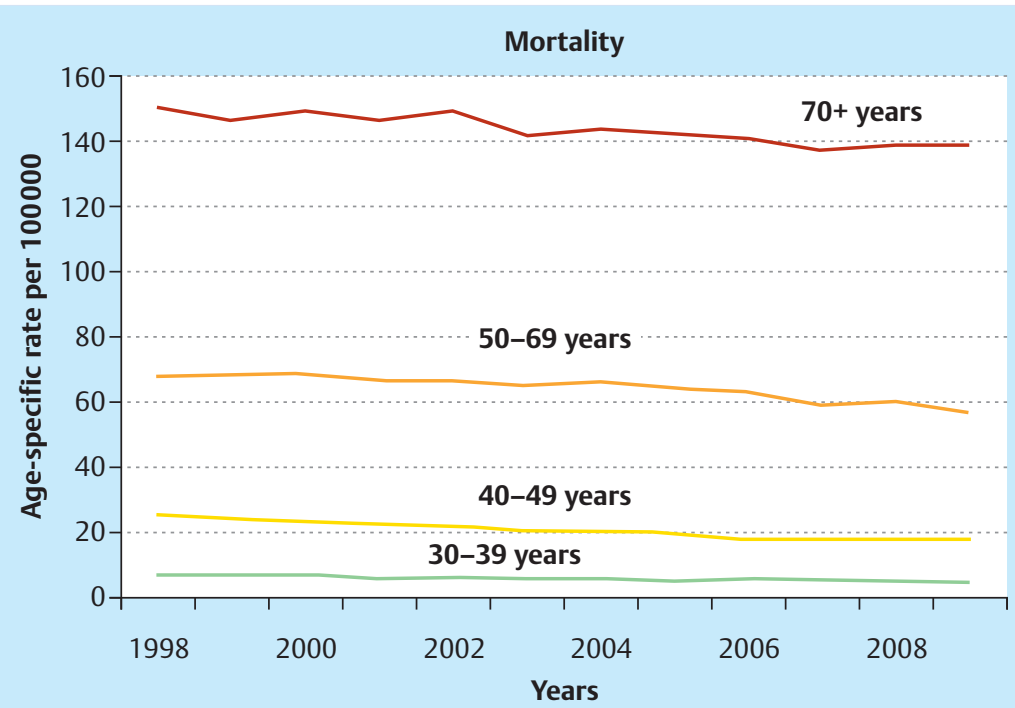

Germany [Gesellschaft der epidemiologischen Krebsregister in Deutschland] and Federal Office of Statistics [Statistisches Bundesamt] [2,9]). 


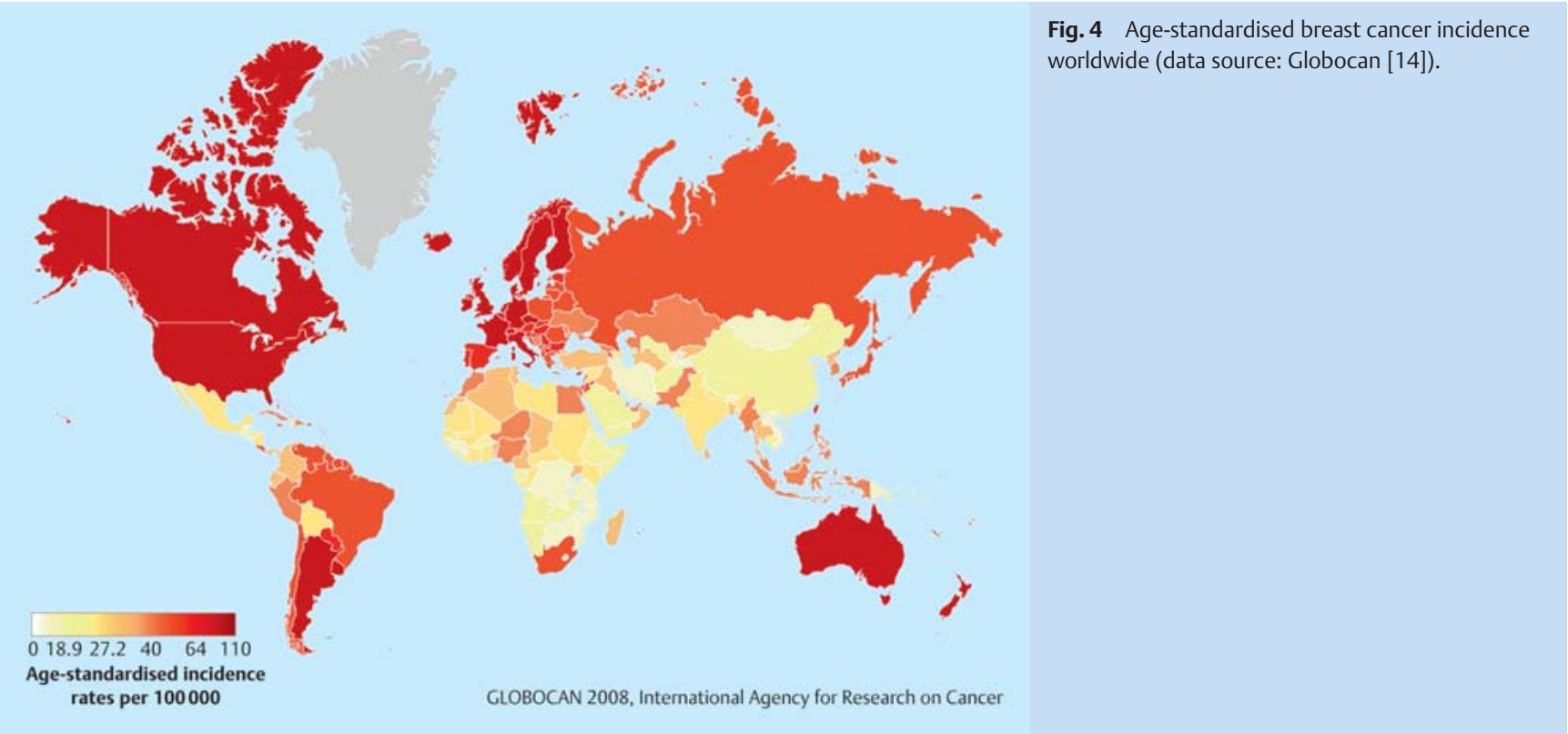

good prognosis lead to the fact that many women who were diagnosed with cancer in the past five years are still alive in these countries. Germany, with a crude rate of 685.3 per 100000 corresponding respectively to around 250000 women who were afflicted with breast cancer within the past 5 years, is in the upper third of the ranking list; this is indicative of a high proportion of prognostically more favourable tumours among the primary disease cases.

\section{Conclusion}

$\nabla$

The epidemiology of breast cancer has changed markedly in the past years, the number of afflicted women has increased further. Currently (in 2009) in Germany around 72000 women suffer from an invasive breast cancer, further 6500 women are diagnosed with an in situ carcinoma of the breast. Thus, breast cancer is the most common cancer diagnosis made for women. Thanks to the increasingly diagnosed favourable tumour stages (40\% T1, $30 \% \mathrm{~T} 2$ ) and the innovations in therapy with a relative 5-year survival of $86 \%$ the prognosis for breast cancer patients can be considered as good. In 2002/2003 the relative survival in Germany and also in the whole of Europe still amounted to 79\% [13]. Today around 250000 women are living in Germany with the diagnosis of breast cancer made during the past 5 years [18].

Mammography screening was introduced in Germany starting in 2005. Complete area coverage was achieved in 2008. Whether or not a further reduction of mortality can be achieved in Germany by means of the systematic examination of women in the age group 50-69 years will be seen in the next few years. A first indication could be the more favourable stage distribution among participants in the mammography screening programme in comparison to an age-matched population before screening started.

\section{Conflict of Interest}

$\nabla$

None.

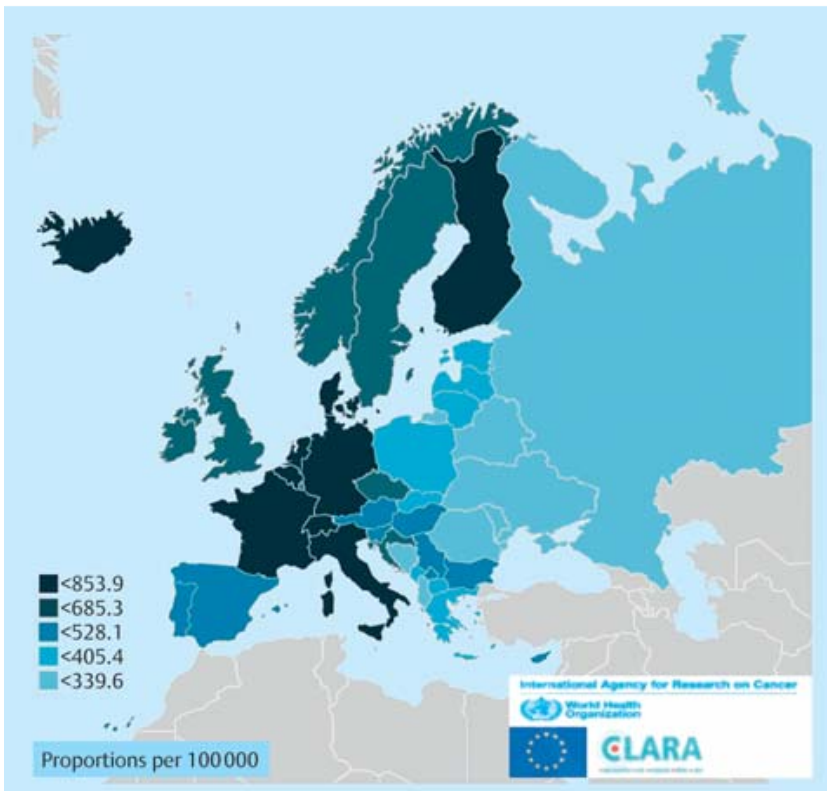

Fig. 5 Five-year breast cancer prevalence in Europe (data source: European Cancer Observatory [15]).

\section{References}

1 Association of Population-based Cancer Registries in Germany (GEKID) and Robert Koch Institute, eds. Cancer in Germany 2007/2008. Incidence and Trends. 8th revised edition. Berlin: 2012

2 Atlas der Krebsinzidenz und -mortalität. Internet: http://www.gekid. de; last access: 8.10.2012

3 Kooperationsgemeinschaft Mammographie, eds. Evaluationsbericht 2008-2009. Ergebnisse des Mammographie-Screening-Programms in Deutschland. Berlin: 2012

4 Gennaro G, Hendrick RE, Ruppel P et al. Performance comparison of single-view digital breast tomosynthesis plus single-view digital mammography with two-view digital mammography. Eur Radiol 2012; Sep 14 [Epub ahead of print] 
5 Michell MJ, Iqbal A, Wasan RK et al. A comparison of the accuracy of film-screen mammography, full-field digital mammography, and digital breast tomosynthesis. Clin Radiol 2012; 67: 976-981

6 Noroozian M, Hadjiiski L, Rahnama-Moghadam S et al. Digital breast tomosynthesis is comparable to mammographic spot views for mass characterization. Radiology 2012; 262: 61-68

7 Svahn TM, Chakraborty DP, Ikeda D et al. Breast tomosynthesis and digital mammography: a comparison of diagnostic accuracy. Br J Radiol 2012; 85: e1074-e1082

8 Albert U-S. Stufe-3-Leitlinie - Brustkrebs-Früherkennung in Deutschland. 1. Aktualisierung. München, Wien, New York: W. Zuckschwerdt Verlag; 2008

9 Gesundheitsberichterstattung des Bundes. Internet: http://www. gbe-bund.de; last access: 8.10.2012

10 Katalinic A, Pritzkuleit $R$, Waldmann A. Recent trends in breast cancer incidence and mortality in Germany. Breast Care 2009; 4: 75-80

11 Esserman L, Shieh $Y$, Thompson I. Rethinking screening for breast cancer and prostate cancer. JAMA 2009; 302: 1685-1692

12 Independent UK Panel on Breast Cancer Screening. The benefits and harms of breast cancer screening: an independent review. Lancet 2012; 380:1778-1786
13 Karim-Kos HE, de Vries E, Soerjomataram I et al. Recent trends of cancer in Europe: a combined approach of incidence, survival and mortality for 17 cancer sites since the 1990s. Eur J Cancer 2008; 44: 1345-1389

14 Globocan 2008 Database. Internet: http://www-dep.iarc.fr/globocan/ database.htm; last access: 8.10.2012

15 ECO website: European Cancer Observatory: Cancer incidence, mortality, prevalence and survival in Europe. Version 1.0 (September 2012). European Network of Cancer Registries, International Agency for Research on Cancer. Internet: http://eco.iarc.fr; last access: 8.10.2012

16 Machleidt A, Diermeier-Daucher S, Mögele M et al. Her4-JMa-Rezeptor als positiv prognostischer Marker in triple negativen Mammakarzinomen. Geburtsh Frauenheilk 2012; 72 - P57

17 Untch $M$. Die neue Leitlinie der Arbeitsgemeinschaft für Gynäkologische Onkologie (AGO) zur operativen Therapie der Axilla bei Mammakarzinom. Geburtsh Frauenheilk 2011; 71 - B25

18 Schmidt M, Fasching PA, Beckmann MW et al. Biomarkers in breast cancer - an update. Geburtsh Frauenheilk 2012; 72: 819-832

19 Lüftner D, Lux MP, Maass $N$ et al. Advances in breast cancer - looking back over the year. Geburtsh Frauenheilk 2012; 72: 1117-1129

20 Kolberg H-C, Lüftner D, Lux MP et al. Breast cancer 2012 - new aspects. Geburtsh Frauenheilk 2012; 72: 602-615

Deutschsprachige Zusatzinformationen online abrufbar unter: www.thieme-connect.de/ejournals/toc/gebfra. 